\title{
The value and appropriateness of positron emission tomography: An evolving tale
}

\author{
Robert C. Hendel, MD \\ University of Miami Miller School of Medicine, Miami, FL \\ Received Jul 21, 2014; accepted Jul 21, 2014 \\ doi: $10.1007 /$ s12350-014-9962-9
}

\section{See related article, pp. 9-15}

The excellence of a gift lies in its appropriateness rather than its value.

\section{Charles Dudley Warner}

The extraordinary advances in medical care during the past several decades have impacted both the quality and longevity of an individual's life. However, impressions of modern health care have been adversely impacted by runaway expenses and the high cost of care delivery., Medical imaging, including nuclear cardiology, has demonstrated excellent value with regards to diagnosis and risk stratification, but has limited date to support its impact on patient outcome, thereby becoming the focus of public and payer attention due to concerns of overuse. $^{1,2}$ This has lead to multiple initiatives to limit test performance and reduce overall spending, including pre-authorization and test substitution. ${ }^{1}$ As a response to fiscal pressures and with a goal of optimizing test/patient selection, appropriate use criteria (AUC) have been developed by several organizations, including the American College of Cardiology (ACC) and American Society of Nuclear Cardiology (AS]NC). ${ }^{3-5}$ Unfortunately, adoption of these AUC by private and federal health plans has been more limited than desired; many private insurers continue to use radiology benefits managers with their proprietary algorithms for test selection, often lacking consistency with medical literature and expert opinion. However, the AUC were specifically designed to serve as guidance documents for

Reprint requests: Robert C. Hendel, MD, 1120 NW 14th Street, CRB

Suite 1123, Miami, FL 33136; rhendel@med.miami.edu

J Nucl Cardiol 2015;22:16-21.

1071-3581/\$34.00

Copyright (C) 2014 American Society of Nuclear Cardiology. clinicians and others with regards to a variety of cardiac tests and procedures.

Positron emission tomography (PET) MPI has been shown to provide improved image quality, superior interpretative confidence, and higher diagnostic accuracy than $\mathrm{SPECT}^{6-12}$ and has been considered by many to be a "gold standard" of non-invasive testing. ${ }^{10}$ In addition to its value as a diagnostic study, the independent and incremental value of myocardial perfusion PET has also been demonstrated in multiple studies, including a multicenter registry involving more than 7,000 patients. ${ }^{11}$ PET possesses a greater discriminatory power than other non-invasive modalities with regards to cardiac events. ${ }^{12}$ Furthermore, rubidium- 82 perfusion PET is associated with a lower radiation burden and more rapid test performance, making this procedure an attractive test for the evaluation of known or suspect ischemic heart disease. ${ }^{10,12}$ However, the costs associated with this procedure are high, as is the level of reimbursement, ${ }^{13}$ which although justifiable based on procedural costs, places additional strain on an already financially overburden health system.

The AUC for radionuclide imaging that were initially published in 2005 were revised and expanded in $2009^{3}$ as a result of technologic advances in nuclear cardiology, feedback from ASNC and individual providers, and improvements in the development of AUC. All of the indications for radionuclide imaging (RNI) are intended for application for both SPECT and PET, unless specifically identified as being germane only to SPECT. The only stipulation regarding the AUC indications impacting PET is that exercise testing is the preferred stress modality for RNI. As exercise PET myocardial perfusion imaging is currently not an option in most centers, this preference is not applicable to PET, although the development of new PET perfusion agents, such as F-18 flurpiridaz, will make exercise testing an option in the future. ${ }^{14}$ Notably, there are no "pure", PET AUC, largely due in part to the similar applications of 
both techniques and the modest amount of PET literature, other than for the detection of ischemic heart disease. However, it is highly likely that these criteria are well suited for both SPECT and PET; the advantages of PET, as noted above, would not likely impact the classification of appropriate use.

In this issue of the Journal, Winchester et $\mathrm{al}^{15}$ report the findings of a retrospective analysis regarding the appropriate use of PET imaging. This unique study is the first report specifically designed to evaluate the AUC for PET and examined not only the categories of appropriate use but also the frequency of abnormal perfusion findings stratified by the level of appropriateness. The authors also describe the relationship of appropriateness to subsequent clinical events.

This study utilized the 2009 RNI AUC, ${ }^{2}$ which have now been largely replaced by the AUC for stable ischemic heart disease, published in 2013 as part of the new multimodality approach. ${ }^{3}$ These new AUC provide an update based on the newest literature but importantly, reflect a number of methodological changes, including new terms for the categories of appropriate use. ${ }^{4}$ The newer terms of "may be appropriate", and "rarely appropriate", are similar to the older terminology of "uncertain" and "inappropriate" but should not be used interchangeably. The new multimodality AUC should replace the 2009 RNI criteria whenever possible. There were 43 indications present in the multimodality AUC that were consistent to those of the RNI AUC, with $35(81 \%)$ rated in a similar appropriateness category, although the definitions and nomenclature for some of the indications contain minor changes. Changes in appropriate categories between the two sets of AUC are noted in Table 1. Although these differences in AUC may somewhat modify the results presented in the current paper, it is doubtful that these will alter its overall impact.

Winchester et $\mathrm{al}^{15}$ found that appropriate and uncertain indications for PET were present in $79.5 \%$ and $10.4 \%$, respectively, with an inappropriate rate of $10.2 \%$. As shown in Table 2, these categorizations for PET appropriate use are similar to those found in the majority of reports with SPECT, ${ }^{16-31}$ although there are some reports of SPECT MPI with higher frequency of inappropriate studies. ${ }^{19,27}$ For evaluation of the scintigraphic findings and outcomes, the authors have combined "appropriate", with "uncertain' categories, which although somewhat controversial, is consistent with the intent of these AUC_- "uncertain is assumed to not provide grounds for denial of reimbursement.",5

A key finding in the current report is the presence of abnormal PET perfusion among all classes of appropriateness, although only $7.7 \%$ of studies performed with an inappropriate indication had abnormal perfusion. However, this low rate of abnormal findings was present even among appropriately indicated studies (28\%). Similarly, abnormal perfusion has been noted in multiple reports of SPECT AUC, even among inappropriate indications, although the frequency of abnormal SPECT findings appears greater than those found in the present PET trial (Table 3). Of note, no ischemia was detected in any of the inappropriate PET examinations in the present report. These overall low rates of abnormal scintigraphic findings may be related to the cohort studied and temporal factors, as there has been a declining rate of abnormal SPECT findings during the several decades, from $>40 \%$ abnormal studies to $<10 \%$. $^{32}$

The next critical and evolutionary step for imaging AUC is to compare outcomes of patients with appropriate vs inappropriately performed procedures. For example, even if an inappropriate test yields abnormal results, is it

Table 1. Differences between the appropriateness categorization based on the 2009 radionuclide imaging (RNI) AUC and the 2013 multimodality (MM) AUC

\begin{tabular}{|c|c|c|}
\hline Indication & 2009 RNI $^{2}$ & $2013 M^{3}{ }^{3}$ \\
\hline High CHD risk asymptomatic & A & M \\
\hline Low CHD risk syncope & I & M \\
\hline Worsening symptoms, normal prior study & $\mathrm{U}$ & A \\
\hline High CHD risk, Agaston score $100-400$ & A & M \\
\hline Agaston score $>400$ & A & M \\
\hline $\begin{array}{l}\text { Preop assessment, intermediate risk surgery, } \\
\geq 1 \text { risk factor with poor functional capacity }\end{array}$ & A & M \\
\hline s/p CABG, asymptomatic, $<5$ years & $\mathrm{u}$ & $\mathrm{R}$ \\
\hline s/p CABG, asymptomatic, $\geq 5$ years & A & M \\
\hline
\end{tabular}

$A$, Appropriate; $M$, may be appropriate; $R$, rarely appropriate; $U$, uncertain; $I$, inappropriate; Agaston score refers to CT-derived calcium scoring. 
Table 2. Classification of appropriate use for SPECT myocardial perfusion imaging

\begin{tabular}{|c|c|c|c|c|c|}
\hline Study & Year & $\mathbf{n}$ & Appropriate (\%) & Uncertain (\%) & Inappropriate (\%) \\
\hline Mehta et al ${ }^{16}$ & 2008 & 1,209 & 80 & 5 & 13 \\
\hline Gibbons et al ${ }^{17}$ & 2008 & 284 & 64 & 11 & 14 \\
\hline Hendel et al ${ }^{18}$ & 2010 & 6,351 & 71 & 15 & 14 \\
\hline Carryer et al ${ }^{19}$ & 2010 & 281 & 60 & 16 & 24 \\
\hline Gibbons et $\mathrm{al}^{20}$ & 2010 & 284 & 66 & 15 & 7 \\
\hline Gholamrezanezhad et al ${ }^{21}$ & 2011 & 291 & 75 & 5 & 14 \\
\hline Druz et $\mathrm{al}^{22}$ & 2011 & 585 & 63 & 20 & 14 \\
\hline Koh et $\mathrm{al}^{23}$ & 2011 & 1,623 & 82 & 5 & 10 \\
\hline Gupta et $\mathrm{al}^{24}$ & 2011 & 314 & 84 & 5 & 11 \\
\hline Aldweib et $\mathrm{al}^{25}$ & 2013 & 1,199 & 62 & 20 & 18 \\
\hline Doukky et al ${ }^{26}$ & 2013 & 1,511 & 52 & 3 & 46 \\
\hline Khawaja et al ${ }^{27}$ & 2013 & 280 & 63 & 14 & 24 \\
\hline Moralidis et $\mathrm{al}^{28}$ & 2013 & 3,032 & 73 & 7 & 19 \\
\hline Medolago et al ${ }^{29}$ & 2014 & 2,134 & 84 & 9 & 7 \\
\hline Lalude et $\mathrm{al}^{30}$ & 2014 & 420 & 77 & 10 & 13 \\
\hline Singh et $\mathrm{al}^{31}$ & 2014 & 328 & 88 & 6 & 7 \\
\hline
\end{tabular}

Percentage may not add to $100 \%$ due to unclassified studies or rounding errors.

Table 3. Abnormal SPECT results and event rates based on appropriate use categories

\begin{tabular}{|c|c|c|c|c|c|}
\hline & Year & $\mathbf{n}$ & A (\%) & $\mathbf{U}(\%)$ & I (\%) \\
\hline \multicolumn{6}{|l|}{ Abnormal results } \\
\hline Mehta et al ${ }^{16}$ & 2008 & 1,209 & 55 & 47 & 32 \\
\hline Gholamrezanezhad et al ${ }^{21}$ & 2011 & 291 & 33 & 47 & 11 \\
\hline Koh et $\mathrm{al}^{23}$ & 2011 & 1,623 & 40 & 21 & 27 \\
\hline Doukky et $\mathrm{al}^{26}$ & 2013 & 1,511 & 40 & 21 & 18 \\
\hline Khawaja et $\mathrm{al}^{27}$ & 2013 & 280 & \multicolumn{2}{|r|}{15} & 7 \\
\hline Medolago et $\mathrm{al}^{29}$ & 2014 & 2,134 & 58 & - & 33 \\
\hline \multicolumn{6}{|l|}{ Events } \\
\hline Druz et $\mathrm{al}^{22 \mathrm{a}}$ & 2011 & 585 & 12 & 7 & 2 \\
\hline Koh et $\mathrm{al}^{36 \mathrm{~b}}$ & 2011 & 176 & 6 & - & 1 \\
\hline Aldweib ${ }^{25 c}$ & 2013 & 1,199 & 10 & 4 & 5 \\
\hline Khawaja et al $^{27 d}$ & 2013 & 280 & 14 & 0 & 3 \\
\hline Medolago et $\mathrm{al}^{29 \mathrm{~d}}$ & 2014 & 2,134 & \multicolumn{2}{|r|}{9} & 3 \\
\hline
\end{tabular}

${ }^{\mathrm{a}} \mathrm{MI}$, death, revascularization, admission.

${ }^{\mathrm{b}}$ Perioperative 90-day major cardiac events.

${ }^{\mathrm{c}}$ Death.

${ }^{\mathrm{d} C}$ Cardiac catheterization.

predictive of subsequent events? To date, we have limited information to answer this type of question, as few SPECT studies have attempted to correlate appropriateness category and scintigraphic findings with patient outcomes (Table 3). Aldweib et $\mathrm{al}^{25}$ demonstrated that SPECT studies done for inappropriate indications had an overall low cardiovascular risk and favorable outcomes when compared with uncertain or appropriately performed examinations. Khawaja et $\mathrm{al}^{26}$ revealed that an inappropriately performed test is less likely to be abnormal but also showed that these patients were less likely to undergo coronary angiography and revascularization. Although $18 \%$ of these patients had an abnormal SPECT study, only $3 \%$ of patients with inappropriate SPECT examinations underwent angiography and none had coronary revascularization. In a large trial of 1,511 consecutive patients, Doukky et $\mathrm{al}^{27}$ demonstrated that inappropriate use of SPECT MPI was associated with 
reduced prognostic value. The hazard ratio for cardiac events, including death and/or myocardial infarction, among patients undergoing SPECT for appropriate or uncertain indications was 3.1-3.7, while those who had SPECT for an inappropriate indication failed to demonstrate discriminatory power with regards to these "hard" endpoints. However, all abnormal SPECT findings were associated with increased rates of coronary revascularization, irrespective of the level of appropriate use. Therefore, an abnormal SPECT MPI, when appropriate, was associated with death and/or MI or other major cardiac events, but if performed for inappropriate indications, the SPECT study did not predict events.

Similar to the SPECT reports describing the prognostic value of AUC, the current report by Winchester et $\mathrm{al}^{15}$ demonstrated that an abnormal PET study or one which possesses significant ischemia (summed difference score $>5$ ) is associated with a hazard ratio for events of 4.5 and 5.1, respectively. Inappropriate PET scans were associated with low angiography rates and the clinical value of these studies appears negligible. The SPECT reports, along with the current paper, provide support for the prognostic implications of RNI AUC, as using radionuclide imaging in an inappropriate fashion fails to detect patients at increased risk for subsequent cardiac events.

However, the literature examining the association of appropriate use with outcomes has major limitations with regards to endpoint selection. The selection of diagnostic catheterization as an endpoint in the investigation by Winchester et $\mathrm{al}^{15}$ and others ${ }^{27}$ is flawed, as physicians were likely biased in their decision to refer a patient for coronary angiography based on scan findings and does not represent a meaningful change in outcome to the patient. Coronary revascularization, while still somewhat subjective, might have been a preferable endpoint except that PCI and CABG were also infrequently performed in the current trail [34 subjects $(6.5 \%)]$, in keeping with the overall low-risk nature of the study cohort. In fact, only $26.1 \%$ had an abnormal study and far fewer had significant ischemia (12.5\%). The selection of objective endpoints, such as death or myocardial infarction, would have been ideal, but these were infrequent events and would have required far more patient to be included in the trial. Not withstanding these limitations, the hypothesis that inappropriate PET (or SPECT) utilization fails to detect patients at increased risk of events or who require additional diagnostic testing/therapeutic intervention is highly thought-provoking and merits additional research.

Few would question the outstanding diagnostic and prognostic utility of PET MPI, with medical evidence not only supporting these applications but also demonstrating cost-effectiveness. ${ }^{10,12}$ The development of new agents, including F-18 flurpiridaz, will likely strengthen the potential value and clinical use of this method, especially given the likelihood of unit dose availability and the further evolution of hybrid imaging. Enthusiasm for widespread clinical application of PET MPI, however, must be tempered with the need for any non-invasive test to have the capacity to impact care management and patient outcomes as well as the recognition of the current fiscal environment in health care. Earlier this year, the United States Congress passed legislation that mandates the use of AUC for advanced medical imaging, including PET, slated to begin in $2017 .^{33}$ Therefore, the evaluation of appropriate use has moved beyond an academic exercise into the mainstream of clinical practice.

The current work is the first to examine the use of AUC for PET imaging and demonstrates that inappropriate PET is infrequently associated with abnormal findings and rarely leads to cardiac catheterization. This further supports the need for the medical community to embrace peer-developed AUC as guidance documents, in order to optimize how we order PET scans and other tests/procedures. It is becoming increasingly evident that the performance of inappropriate radionuclide imaging is far less likely to achieve care goals but when performed appropriately may limit downstream unnecessary clinical consequences, such as angiography and revascularization. The development and now validation of AUC for PET and other methods must move beyond statistical correlations to direct patient impact. Fortunately the ACC/ASNC AUC for radionuclide imaging are ideally suited to an algorithmic approach and are now being embedded into web-based tools ${ }^{34}$ and clinical decision support instruments. ${ }^{35}$ Placing the AUC into the clinical realm for use at the time of ordering will hopefully allow practitioners to optimize their use of cardiac imaging, emphasizing clinical value, with recognition of cost. Studies to date have been encouraging with this approach, especially when coupled with additional educational initiatives. ${ }^{33,34}$ Through continued efforts to optimize use of PET MPI, the true promise of this remarkable technique will be realized.

\section{References}

1. Hendel RC. Utilization management of cardiovascular imaging. J Am Coll Cardiol 2008;1:241-8.

2. Iglehart JK. The new era of medical imaging-Progress and pitfalls. N Engl J Med 2009;360:1030-7.

3. Hendel RC, Berman DS, Di Carli MF, Heidenreich PA, Henkin RE, Pellikka PA, et al. ACCF/ASNC/ACR/AHA/ASE/SCCT/ SCMR/SNM 2009 appropriate use criteria for cardiac radionuclide imaging: A report of the American College of Cardiology Foundation Appropriate Use Criteria Task Force, the American Society of Nuclear Cardiology, the American College of Radiology, the American Heart Association, the American Society of Echocardiography, the Society of Cardiovascular Computed Tomography, 
the Society for Cardiovascular Magnetic Resonance, and the Society of Nuclear Medicine. J Am Coll Cardiol 2009;53:2201-29.

4. Wolk MJ, Bailey SR, Doherty JU, Douglas PS, Hendel RC, Kramer CM, et al. ACCF/AHA/ASE/ASNC/HFSA/HRS/SCAI/ SCCT/SCMR/STS 2013 multimodality appropriate use criteria for the detection and risk assessment of stable ischemic heart disease: A report of the American College of Cardiology Foundation Appropriate Use Criteria Task Force, American Heart Association, American Society of Echocardiography, American Society of Nuclear Cardiology, Heart Failure Society of America, Heart Rhythm Society, Society for Cardiovascular Angiography and Interventions, Society of Cardiovascular Computed Tomography, Society for Cardiovascular Magnetic Resonance, and Society of Thoracic Surgeons. J Am Coll Cardiol 2014;63:380-406.

5. Hendel RC, Patel MR, Allen JM, Min JK, Shaw LJ, Wolk MJ, et al. Appropriate use of cardiovascular technology: 2013 ACCF appropriate use criteria methodology update: A report of the American College of Cardiology Foundation Appropriate Use Criteria Task Force. J Am Coll Cardiol 2013;61:130517.

6. Bateman TM, Heller GV, McGhie AI, Friedman JD, Case JA, Bryngelson JR, et al. Diagnostic accuracy of rest/stress ECG-gated Rb-82 myocardial perfusion PET: Comparison with ECG-gated Tc-99m sestamibi SPECT. J Nucl Cardiol 2006;13:24-33.

7. Flotats A, Bravo PE, Fukushima K, Chaudhry MA, Merrill J, Bengel FM. Rb-82 PET myocardial perfusion imaging is superior to Tc-99 Tc-labelled agent SPECT in patients with known or suspected coronary artery disease. Eur J Nucl Med Mol Imaging 2012;39:1233-9.

8. Mc Cardle BA, Dowsley TF, deKemp RA, Wells GA, Beanlands RS. Does rubidium-82 PET have superior accuracy to SPECT perfusion imaging for the diagnosis of obstructive coronary disease: A systematic review and meta-analysis. J Am Coll Cardiol 2012;60:1828-37.

9. Parker MW, Iskandar A, Limone B, Perugini A, Kim H, Jones C, et al. Diagnostic accuracy of cardiac positron emission tomography versus single photon emission computed tomography for coronary artery disease: A bivariate meta-analysis. Circ Cardiovasc Imaging 2012;5:700-7.

10. Bengel FM, Higuchi T, Javadi MS, Lautamaki R. Cardiac positron emission tomography. J Am Coll Cardiol 2009;54:1-15.

11. Dorbala S, Di Carli MF, Beanlands RS, Merhige ME, Williams BA, Veledar E, et al. Prognostic value of stress myocardial perfusion positron emission tomography: Results from a multicenter observational registry. J Am Coll Cardiol 2013;61:176-84.

12. Shaw LJ, Hage FG, Berman DS, Hachamovitch R, Iskandrian A. Prognosis in the era of comparative effectiveness research: Where is nuclear cardiology now and where should it be? J Nucl Cardiol 2012;19:1026-43.

13. Medicare Hospital Outpatient Prospective Payment System, ASNC website, http://www.asnc.org/media/ASNC\%20HOPPS\% 20Final\%20Payment $\% 20$ Chart $\% 202014 \% 20 \% 2812513 \% 29$.pdf. Accessed 2 July 2014.

14. Berman DS, Maddahi J, Tamarappoo BK, Czwenin J, Taillefer R, Udelson JE, et al. Phase II safety and clinical comparison with single-photon emission computed tomography myocardial perfusion imaging for the detection of coronary artery disease: Flurpiridaz F18 positron emission tomography. J Am Coll Cardiol 2013;61:469-77.

15. Winchester D, Randall M, Chauffe R, Meral R, Nguyen D, Ryals $\mathrm{S}$, et al. Clinical utility of inappropriate positron emission tomography myocardial perfusion imaging: Test results and cardiovascular events. J Nucl Cardiol 2014. doi:10.1007/s12350014-9925-1.
16. Mehta R, Ward PR, Chandra S, Agarwal R, Williams KA. Evaluation of the American College of Cardiology Foundation/ American Society of Nuclear Cardiology appropriateness criteria for SPECT myocardial perfusion imaging. J Nucl Cardiol 2008;15:337-44.

17. Gibbons RJ, Miller TD, Hodges D, Urban L, Araoz PA, Pelikka P, et al. Application of appropriateness criteria to stress single-photon emission computed tomography sestamibi studies and stress echocardiograms in an academic medical center. J Am Coll Cardiol 2008;51:1283-9.

18. Hendel RC, Cerqueira M, Douglas PS, Caruth KC, Allen JM, Jensen NC, et al. A multicenter assessment of the use of singlephoton emission computed tomography myocardial perfusion imaging with appropriateness criteria. J Am Coll Cardiol 2010;55:156-62.

19. Carryer DJ, Hodge DO, Miller TD, Askew JW, Gibbons RJ. Application of appropriateness criteria to stress single photon emission computed tomography sestamibi studies: A comparison of the 2009 revised appropriateness criteria to the 2005 original criteria. Am Heart J 2010;160:244-9.

20. Gibbons RJ, Askew JW, Hodge D, Miller TD. Temporal trends in compliance with appropriateness criteria for stress single-photon emission computed tomography sestamibi studies in an academic medical center. Am Heart J 2010;159:484-9.

21. Gholamrezanezhad A, Shirafkan A, Mirpour S, Rayatnavaz M, Alborzi A, Mogharrabi M, et al. Appropriateness of referrals for single-photon emission computed tomography myocardial perfusion imaging (SPECT-MPI) in a developing community: A comparison between 2005 and 2009 versions of the ACCF/ASNC appropriateness criteria. J Nucl Card 2011;18:1044.

22. Druz RS, Phillips LM, Sharifova G. Clinical evaluation of the appropriateness use criteria for single-photon emission computed tomography: Differences by patient population, physician specialty and patient outcomes. ISRN Cardiol 2011;2011:798318.

23. Koh AS, Flores JLS, Keng FYJ, Tan RS, Chua TSJ. Evaluation of the American College of Cardiology Foundation/American Society of Nuclear Cardiology appropriateness criteria for SPECT myocardial perfusion imaging in an Asian tertiary cardiac center. $\mathrm{J}$ Nucl Cardiol 2011;18:324-30.

24. Gupta A, Tsiara SV, Dunsiger SI, Tilkemeier PL. Gender disparity and the appropriateness of myocardial perfusion imaging. J Nucl Cardiol 2011;18:588-94.

25. Aldweib N, Negishi K, Seicean S, Jaber WA, Hachamovitch R, Cerqueira $\mathrm{M}$, et al. Appropriate test selection for single-photon emission computed tomography imaging: Association with clinical risk, posttest management, and outcomes. Am Heart J 2013; 166:581-8.

26. Doukky R, Hayes K, Frogge N, Balakrishnan G, Dontaraju VS, Rangel MO, et al. Impact of appropriate use on the prognostic value of single-photon emission computed tomography myocardial perfusion imaging. Circulation 2013;128:1634-43.

27. Khawaja FJ, Jouni H, Miller RD, Hodge DO, Gibbons RJ. Downstream clinical implications of abnormal myocardial perfusion single-photon emission computed tomography based on appropriate use criteria. J Nucl Cardiol 2013;20:1041-8.

28. Moralidis E, Papadimitrious N, Stathaki M, Xourgia X, Spyridonidis T, Fotopoulos A, et al. A multicenter evaluation of the appropriate use of single-photon emission tomography myocardial perfusion imaging in Greece. J Nucl Cardiol 2013;20:275-83.

29. Medolago G, Marcassa C, Alkraisheh A, Campini R, Ghilardi A, Giubbini R, et al. Applicability of the appropriate use criteria for SPECT myocardial perfusion imaging in Italy: Preliminary results. Eur J Nucl Med Mol Imaging 2014. doi:10.1007/s00259-0142743-5. 
30. Lalude OO, Gutarra MF, Pollono EM, Lee S, Tarwater PM. Inappropriate utilization of SPECT myocardial perfusion imaging on the USA-Mexico border. J Nucl Cardiol 2014;21:544-52.

31. Singh M, Babayan Z, Harjai KJ, Dedhia P, Sattur S, Jagasia DH. Utilization patterns of single-photon emission cardiac tomography myocardial perfusion imaging studies in a rural tertiary care setting. Clin Cardiol 2014;37:67-72.

32. Rozanski A, Gransar H, Hayes SW, Min J, Friedman JD, Thomson LE, et al. Temporal trends in the frequency of inducible myocardial ischemia during cardiac stress testing: 1991 to 2009. J Am Coll Cardiol 2013;61:1054-65.

33. Text of the Protecting Access to Medicare Act of 2014, https://www.govtrack.us/congress/bills/113/hr4302/text. Accessed 2 July 2014
34. Saifi S, Taylor AJ, Allen J, Hendel R. The use of a learning community and online evaluation of utilization for SPECT myocardial perfusion imaging. JACC Cardiovasc Imaging 2013;6:823-9.

35. Lin FY, Dunning AM, Narula J, Shaw LJ, Gransar H, Berman DS, et al. Impact of an auto mated multimodality point-of-order decision support tool on rates of appropriate testing and clinical decision making for individuals with suspected coronary artery disease: A prospective multicenter study. J Am Coll Cardiol 2013;62:308-16.

36. Koh AS, Flores JLS, Keng FYJ, Tan RS, Chua TSJ. Correlation between clinical outcomes and appropriateness grading for referral to myocardial perfusion imaging for preoperative evaluation prior to non-cardiac surgery. J Nucl Cardiol 2012;19:27784. 